Joaquín Sorolla (1863-1923)

\title{
Unter der Sonne Spaniens
}

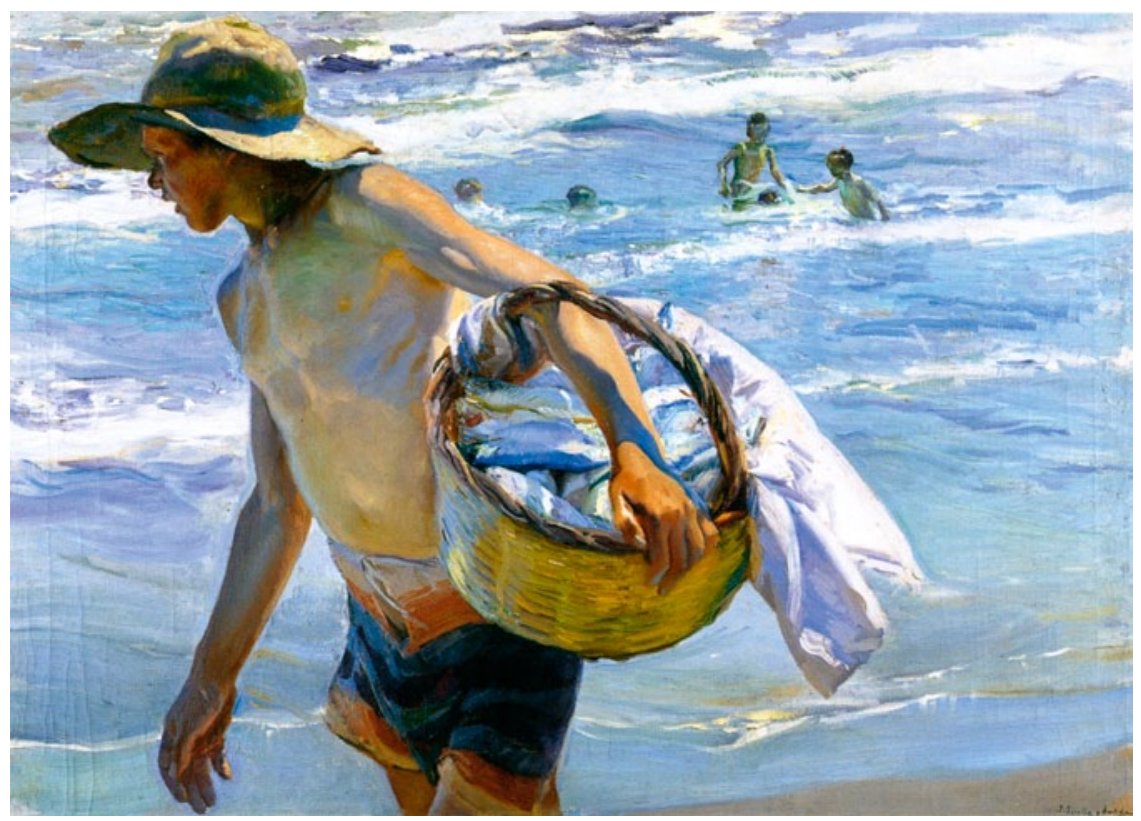

Joaquín Sorolla „Junger Fischer, Valencia“ (1904)

\section{Joaquín Sorolla gilt als der einzige spanische Impressionist von Weltruhm. Eindrucksvoll sind seine Gemälde von Menschen und Landschaften im Sonnenlicht seines Heimatlandes.}

m Jahre 2009 fand im Prado-Museum der Stadt Madrid die umfassendste Retrospektive der Werke des spanischen Malers Joaquín Sorolla y Bastida statt. Bereits 2005 war eine umfangreiche Monographie der Urenkelin Blanca PonsSorolla erschienen, dessen Umschlagbild „The white boat, Jávea“ (1905) auch die Titelseite dieser Ausgabe ziert.

Mit seinen Darstellungen des durch Fischersegel scheinenden, durch Strandkleider gefilterten oder auf der nackten Haut badender Kinder schimmernden mediterranen Lichts ist er berühmt geworden. In immer neuen Variationen hat er die Reflexion der Lichtpartikel auf den Gegenständen eingefangen. Er malte, was er sah. Sein Pinsel konnte einfach alles!

Sorolla wurde am 27. Februar 1863 in Valencia geboren. Bereits im Alter von zwei Jahren wurde er Vollwaise, nachdem seine Eltern an der Cholera verstorben waren. Früh wurde in der Schule sein Zeichentalent erkannt, sodass er schon mit 15 Jahren die Kunstschule in Valencia besuchte und Zeichenunterricht bei einem bekannten Bildhauer erhielt. Drei Jahre später lernte er im Prado die Gemälde von El Greco, Ribera und Velázques kennen und kopierte sie. Nach seiner ersten erfolgreichen Ausstellung in seiner Heimatstadt erhielt er ein Stipendium, mit dem er im Alter von 21 Jahren einen Studienaufenthalt in Rom finanzierte. In Paris begeisterte er sich ab 1885 für die moderne Kunst, insbesondere die Impressionisten.

1888 heiratete Sorolla die Schwester eines Mitschülers Clotilde García del Castello. Danach kamen die Kinder María
Clotilde, Joaquín und Elena zur Welt, die er immer wieder abbildete. In Madrid niedergelassen, malte er zunächst im realistischen Stil historische Themen, dann aber immer wieder Bilder von Fischern. Mit diesen Gemälden gewann er etliche Preise. Auf der Pariser Weltausstellung im Jahr 1900 erhielt er eine Ehrenmedaille. Nach einer Einladung 1909 durch den Spanien-Enthusiasten und Sohn eines Eisenbahnmagnaten Archer Huntington nach New York erhielt Sorolla den Großauftrag, die Bibliothek der Hispanic Society of America auszugestalten. Bis 1919 entstanden 14 gigantische Wandbilder von fünf bis $14 \mathrm{~m}$ Breite mit den Darstellungen der spanischen Geschichte und spanischer Persönlichkeiten.

\section{Rund 4.000 Werke geschaffen}

Sorolla entwickelte aus den Erfahrungen mit der klassischen, aber auch realistischen Malerei und den impressionistischen Eindrücken seinen eigenen unvergleichlichen Kunststil. Auf seinen Reisen durch Europa und nach Amerika bekam er viel Anerkennung in der Kunstszene. Sorollas Werke mit kühnen Kompositionen sind vor allem durch die Ausgeglichenheit von Hell und Dunkel, von Licht und Schatten gekennzeichnet. Gerade seine Strandszenen zeigen einen Lichtzauber. Er war ungeheuer fleißig und hat mit Historien-, Genre-, religiösen und Landschafts-Bildern sowie Porträts über 4.000 Ölgemälde und Aquarelle geschaffen, die bei Privatsammlern auch heute sehr beliebt sind. Die Arbeit im Freien wurde Sorollas Markenzeichen. Sein Strandbild "Junger Fischer; Valencia“ (Abb.) erzielte Ende des Jahres 2010 immerhin 3,6 Mio. Euro.

Nach dem Tod seiner Ehefrau Clotilde vermachte er sein Madrider Haus und eine große Zahl seiner Gemälde dem spanischen Staat. Hier entstand das Museo Sorolla in Madrid, dessen erster Direktor sein Sohn Joaquín Sorolla wurde. 1914 ernannte man den einzigen spanischen Impressionisten von Weltgeltung Joaquín Sorolla zum Dozenten für Farben und Komposition an der Kunstschule in Madrid. 1920 erlitt er eine Halbseitenlähmung, von der er sich nicht mehr erholte. Er starb am 10. August 1923 in Cercedilla.

Dr. Joachim Gunkel, Dannewerk 